\title{
Produção do cuidado a pessoas com hipertensão arterial: acolhimento, vínculo e corresponsabilização
}

\author{
Caring production for people with high blood pressure: reception, bonding and co-responsibility \\ Producción del cuidado a personas con hipertensión arterial: acogida, vínculo y responsabilidad compartida
}

\author{
Leilson Lira Lima', Thereza Maria Magalhães Moreira", Maria Salete Bessa Jorge" \\ ' Universidade Estadual do Ceará, Centro de Ciências da Saúde, \\ Programa de Pós-Graduação em Saúde Coletiva (Mestrando). Fortaleza-CE, Brasil. \\ "Universidade Estadual do Ceará, Centro de Ciências da Saúde, \\ Programa de Pós-Graduação em Saúde Coletiva. Fortaleza-CE, Brasil.
}

Submissão: 21-03-2012 Aprovação: 15-07-2013

\section{RESUMO}

Objetivou-se compreender como têm sido utilizados o acolhimento, o vínculo e a corresponsabilização na construção do cuidado aos usuários com hipertensão arterial. Pesquisa qualitativa realizada em Fortaleza-CE, em um Centro de Saúde da Família (CSF), teve como participantes nove trabalhadores de saúde e dez usuários. Para a coleta das informações foram utilizadas entrevista semiestruturada e observação sistemática. A análise dos achados foi realizada a partir de análise categorial temática. Os resultados mostraram que o acolhimento é utilizado na perspectiva de garantir acesso dos usuários com hipertensão arterial, como etapa do processo de trabalho (triagem) e como relação intercessora entre os sujeitos. Observou-se a construção do vínculo, bem como os usuários referiram satisfação com o atendimento. A responsabilização clínica existe, contudo não é corresponsável, não ajuda na produção da autonomia dos usuários no processo saúde-doença-cuidado. Considera-se de fundamental importância o uso destas tecnologias leves, garantindo acompanhamento e evitando possíveis intercorrências.

Descritores: Cuidado em Saúde; Acolhimento; Hipertensão.

ABSTRACT

This study aimed to understand how the devices of reception, bonding and co-responsibility have been used in the construction of care to patients with high blood pressure. Qualitative research conducted in Fortaleza, in a Family Health Center (FHC), which has, as participants, nine health workers and ten patients. For the collection of information it was used semi-structured interviews and systematic observation. The analysis of findings was performed through the thematic categorical analysis. The results showed that the reception is used with a way to ensure access for users with hypertension, as a step in the work process (screening) and as intercessory relationship between subjects. It was observed the construction of bonding, as well as patients reported satisfaction with the service. The clinical responsibility exists, yet there is no co-responsibility, not helping in the production of patient's autonomy in the health, disease and care. It is of mayor importance the use of these soft technologies, ensuring, monitoring and preventing possible complications.

Key words: Care Health; Reception; High Blood Pressure.

\section{RESUMEN}

Se objetivó comprender como se lleva a cabo los dispositivos de acogida, vínculo y co-responsabilización en la construcción del cuidado a personas con hipertensión arterial. Pesquisa cualitativa realizada en Fortaleza-CE, en Centro de Salud de la Familia (CSF), y tuvo como participantes nueve trabajadores y diez usuarios. Para colecta de informaciones fueran utilizadas la entrevista semi estructurada y observación sistematizada. El análisis de datos fue orientado por análisis categorial temático. Los resultados mostraran que la acogida es utilizada en la perspectiva de garantir acceso a los usuarios con hipertensión arterial, como fase del proceso de trabajo (clasificación), y como relaciones entre los sujetos. Se observó que existe construcción del vínculo, así como los usuarios relataron satisfacción con el cuidado. La responsabilización clínica existe, todavía no se caracteriza como co-responsable, no ayuda en producción de autonomía de los usuarios en el proceso salud, enfermedad y cuidado Se concluye que es fundamental el uso de estas tecnologías leves, garantiendo consultas y previendo posibles complicaciones.

Palabras clave: Cuidado en Salud; Acogida; Hipertensión.

\section{AUTOR CORRESPONDENTEＬeilson Lira Lima E-mail: leilsonlira@hotmail.com}




\section{A TEMÁTICA EM QUESTÃO}

O cuidado em saúde está aberto à presença do trabalho vivo em ato, ou seja, pode ser realizado a partir das relações entre os sujeitos, situando-se em torno de tecnologias leves como acolhimento, vínculo e corresponsabilização o que possibilita ao trabalhador criar espaços para que sejam considerados desejos e afetos, seus e dos usuários ${ }^{(1)}$.

O acolhimento representa a interação entre trabalhador de saúde e usuário e se conforma como uma prática permeada de ações comunicacionais, atos de receber e ouvir aqueles que procuram o serviço, fornecendo respostas às demandas dos usuários, seja na recepção ou consulta individual ${ }^{(2)}$, isto é, não se configura como atendimento em si, mas conteúdo de todo atendimento. Além disso, consiste na busca constante do reconhecimento das necessidades de saúde dos usuários e das formas possíveis de satisfazê-las ${ }^{(3)}$.

Pode-se afirmar, portanto, que o acolhimento é processo, resultado de práticas de saúde, produto da relação entre trabaIhadores de saúde e usuários e acontece também no momento do atendimento. Ademais, ele enseja posturas ativas, por parte dos trabalhadores para com as necessidades dos usuários, resgata a humanização e o respeito para com o outro e envolve a garantia de acessibilidade, bem como a responsabilização pelos problemas dos usuários.

Nesse sentido, a Política Nacional de Humanização(4) considera o acolhimento como importante dispositivo para a consolidação de práticas de cuidado, sobretudo na Atenção Primária, que valorizem o usuário e resgate sua cidadania. A partir do acolhimento, pode-se reduzir e tempo de espera e as filas, além de promover a hierarquização de riscos, ampliando, assim, o acesso e garantindo o acompanhamento dos usuários em seu percurso terapêutico.

Outro instrumento de trabalho relacional é o vínculo o qual permite a circulação de afetos entre pessoas, além de se constituir em ferramenta eficaz na horizontalização e democratização das práticas de cuidado, pois favorece a negociação entre os sujeitos envolvidos nesse processo. A construção do vínculo, portanto, centra-se na formação de laços afetivos entre trabalhadores e usuários, ou seja, no receber bem cada usuário que comparece ao serviço, na confiança e na facilidade de comunicação entre esses atores ${ }^{(5)}$. Considera-se que as dimensões deste dispositivo também perpassam pela humanização dos serviços e como ato de troca de saberes entre usuários e trabalhadores que qualifica a escuta aos problemas e necessidades de saúde e compreende o sofrimento do outro ${ }^{(6)}$.

O vínculo guarda estreita relação com a capacidade do outro para usufruir da condição de sujeito ativo, autônomo nas decisões acerca de sua vida. É, portanto, o dispositivo que leva trabalhadores e usuário ao encontro de suas potencialidades, pois favorece a reciprocidade de experiências e, assim, possibilita a construção de atos terapêuticos corresponsabilizados e coautorais ${ }^{(7)}$.

Deste modo, deve existir uma atenção acolhedora, construída pelo vínculo e corresponsabilização como maneira de produzir um cuidado que considere as opiniões e as possibilidades dos trabalhadores e usuários na composição de um determinado projeto terapêutico ${ }^{(8)}$, não esquecendo do contexto em que esses atores estão inseridos.

É nesta perspectiva que se situa o objeto deste estudo, acoIhimento, vínculo e corresponsabilização no cuidado às pessoas com hipertensão arterial (HA). Esta enfermidade faz parte das doenças crônicas não infecciosas (DCNI) com crescente aumento, acometendo aproximadamente, $30 \%$ da população mundial, com previsão de aumento de $60 \%$ da doença até 2025 e associa-se, com frequência, a alterações funcionais e/ ou estruturais dos órgãos-alvo (coração, encéfalo, rins e vasos sanguíneos), disfunções metabólicas e risco de eventos cardiovasculares fatais e não fatais ${ }^{(9)}$.

Com o objetivo de prevenir o aparecimento dessas complicações, promover a saúde e prestar atendimento às pessoas com HA foi desenvolvido no ano de 2001 o Plano de Reorganização da Atenção à Hipertensão Arterial e ao Diabetes Mellitus do Ministério da Saúde, dentro das Ações Programáticas do Governo Federal ${ }^{(10)}$. Entretanto, alguns estudos ${ }^{(11)}$ revelam que o cuidado que se constrói no cotidiano dos serviços é centrado apenas nas tecnologias duras e leve-duras, direcionado para a abordagem de queixa-conduta, centrada no ato prescritivo, sem a interação entre trabalhadores e usuários e anulando a importância dos espaços de fala e escuta na produção do cuidado.

Embora esses "modos de cuidado" sejam burocratizados, sumarizados e com pouco manuseio de tecnologias leves, algumas experiências mostram possibilidades de cuidar para além desse ato prescritivo. Tais experiências ${ }^{(12)}$ revelam um cuidado integral na atenção primária com práticas de acolhimento, vínculo e corresponsabilização da equipe multiprofissional, existência de grupos de educação em saúde e ações de promoção direcionadas à comunidades induzem a resultados favoráveis na assistências às pessoas com $\mathrm{HA}$, tais como: meIhora na adesão ao tratamento farmacológico e não farmacológico, diminuição dos encaminhamentos a outros níveis atenção e às urgências e emergências.

Além disso, pode-se afirmar que o acolhimento e vínculo no cuidado às pessoas com HA visam mudanças quanto às dificuldades enfrentadas para conseguir atendimento, receber informação adequada por parte do serviço de saúde, conseguir consulta e, mediante agendamento, garantir retorno a estes usuários. Com isso, evitam-se constrangimentos, sofrimentos e abandono do acompanhamento devido aos aborrecimentos das constantes filas ou pelo fato de deixarem de ser atendidos ${ }^{(5)}$.

Destaca-se que o cuidado aos usuários com hipertensão arterial deve ser produzido a partir das tecnologias leves em consonância com as duras e leve-duras. Sendo assim, não se podem descartar os saberes provenientes da clínica, a possibilidade de terapia farmacológica, adesão ao tratamento e mudança no estilo de vida. Porém, face ao exposto até aqui com relação aos dispositivos acolhimento, vínculo e corresponsabilização, acredita-se que estas tecnologias relacionais podem estimular a autonomia do usuário em seu projeto terapêutico, garantir acessibilidade às consultas e, assim, reduzir possíveis intercorrências advindas deste processo de adoecimento.

Neste sentido, é necessário compreender que a resolutividade da atenção às pessoas com HA "consiste não apenas no uso medicamento e na instituição de medidas reguladoras, 
mas na consideração da pessoa em sua totalidade"(13).

Embora a literatura científica aponte a importância destes dispositivos na saúde em geral (2,6-8,14-15), poucas produções discutem sua utilização no cuidado às pessoas com $\mathrm{HA}^{(16)}$. Contudo, ressalta-se que a reflexão sobre as interfaces do cuidado às pessoas com HA e o contexto de vida dos sujeitos são discutidas na literatura brasileira ${ }^{(11,13,16)}$.

Diante desta incipiente produção no campo das tecnologias do cuidado, entende-se que o presente estudo contribui com novos arranjos tecnológicos na atenção individual e coletiva e na (re)construção de novos saberes e práticas dos sujeitos envolvidos nesta atenção, entre eles o profissional de enfermagem.

Esta pesquisa, portanto, tem o objetivo de compreender como têm sido mobilizados os dispositivos - acolhimento, vínculo e corresponsabilização no cuidado aos usuários com HA. Para tanto, elaborou-se como questão norteadora: Quais os cuidados prestados pelos trabalhadores de saúde que geram acolhimento, vínculo e corresponsabilização às pessoas com hipertensão arterial?

\section{METODOLOGIA}

Esta pesquisa é de natureza qualitativa e foi realizada no município de Fortaleza-CE. Em Fortaleza existem 91 Centros de Saúde da Família (CSF), distribuídos em 114 bairros, todos com a Estratégia Saúde da Família (ESF) implantada com uma cobertura de $43 \%$, ainda longe do ideal de $100 \%$, mas com avanço, pois até 2006 essa cobertura era de apenas 15\% ${ }^{(17)}$.

O município de Fortaleza encontra-se dividido política e administrativamente em seis Secretarias Executivas Regionais (SER), todas responsáveis pela gestão dos serviços de saúde na sua respectiva área de abrangência ${ }^{(17)}$. Desta forma, o lócus da pesquisa foi um Centro de Saúde da Família pertencente a uma SER.

No CSF estudado, existem três equipes da ESF que atendem três bairros e cerca de 400 a 500 usuários com hipertensão. O CSF possui consultórios odontológicos, médicos, consultórios de enfermagem, sala de vacina, de aerossolterapia e procedimentos antropométricos, de curativo, sala de prevenção citopatológica, farmácia e amplo espaço de recepção a qual conta com serviço de marcação de consultas internas (no CSF), a especialistas e exames. Ainda na recepção, observou-se que este espaço conta com cadeiras em número considerável, cartazes e murais com informações sobre o atendimento do CSF investigado e campanhas de saúde.

Vale destacar que nas constantes visitas realizadas para a aproximação com o campo e coleta dos dados deste estudo, constatou-se poucas filas na recepção. Além disso, não cabe à recepção a decisão sobre o atendimento ao usuário, ficando-o sob a responsabilidade do profissional que realiza o acolhimento, ainda que a recepção seja o primeiro contato do usuário no CSF.

Como a localização deste centro de saúde é defronte a uma avenida com intenso tráfego de veículos e compreendendo que parte das pessoas com HA são idosos, o atendimento ocorre em grupos localizados no território de abrangência das equipes, como salão de igrejas e no Centro de Referência em Assistência Social (CRASS) localizado ao lado do CSF, objetivando evitar acidentes, facilitar e garantir o acesso ao referido serviço de saúde.

Os sujeitos do estudo foram selecionados por amostragem intencional. Iniciamos a pesquisa com 24 sujeitos, trabalhadores e usuários, mas este número de participantes foi delimitado pelo processo de saturação teórica. Assim, na medida em que fomos coletando e analisando o material empírico, as estruturas de relevância foram aprofundando-se e respondendo aos objetivos traçados ${ }^{(18)}$.

Com isso, o número final de participantes limitou-se a dezenove, distribuídos em dois grupos: grupo I - trabalhadores de saúde que atuam diretamente no cuidado às pessoas com $\mathrm{HA}$ e trabalham há mais de um ano no CSF em estudo (02 médicos, 03 enfermeiros, 02 auxiliares de enfermagem e 01 agente comunitários de saúde) e grupo II - dez usuários com hipertensão arterial que recebem atendimento por igual período.

A coleta ocorreu entre os meses de maio e julho de 2011, após aprovação do projeto pelo Comitê de Ética em Pesquisa da Universidade Estadual do Ceará, que avaliou a pertinência deste, os objetivos da pesquisa e os riscos e/ou benefícios a que estariam submetidos os participantes da investigação, de acordo com a Resolução 196/96, do Conselho Nacional de Saúde ${ }^{(19)}$. Posteriormente a aprovação, enviamos uma cópia do projeto ao Serviço de Protocolo da Secretaria Municipal de Saúde para a avaliação da coordenadora do Sistema Municipal de Saúde Escola visando à realização no Centro de Saúde da Família selecionado.

Foram utilizadas como técnica de coleta das informações a entrevista semiestruturada e a observação sistemática a qual realizou a visão direta das peculiaridades da produção do cuidado e seus dispositivos analisados (acolhimento, vínculo e corresponsabilização): rotinas, detalhes, inter-relações, participações, conversas e motivações ${ }^{(20)}$.

A entrevista foi escolhida pelas suas características que atendem aos objetivos da pesquisa. Pois se trata de uma forma de comunicação verbal, na qual se pode visualizar o que foi dito, percebendo algo do sentido e não expressado.

Entende-se que a produção do cuidado ocorre dialogicamente entre os diversos atores dos serviços de saúde, constituindo-se, portanto, pela comunicação. Esta por sua vez estabelece-se, dentre outros elementos, pela palavra, que é significante e controversa, ao mesmo tempo em que pode revelar códigos, valores, símbolos e normas. Sendo assim, pela entrevista, que também forma de comunicação pela palavra, se pode ver o significado do objeto, seu alcance, sua importância e as consequências para o sujeito, revelando ou descobrindo o sujeito em suas inter-relações, seu cotidiano, seus conflitos e suas contradições ${ }^{(20)}$.

Para a análise dos achados, optou-se pela análise categorial temática ${ }^{(21)}$, percorrendo suas três etapas operacionais: pré-análise, a análise e exploração do material coletado e o tratamento dos achados e interpretação. Esta técnica de análise permite passar dos elementos descritivos à compreensão e interpretação dos discursos dos sujeitos imbricados com processo de construção do cuidado às pessoas com $\mathrm{HA}$, no contexto cultural em que produziram a informação, verificando-se a influência desse contexto no estilo, na forma e no conteúdo 
dos discursos. As falas que emergiram das entrevistas foram identificadas da seguinte forma: usuários (Usu, numerados de 1 a 10) e trabalhadores de saúde (Med, Enf, Aux e ACS, numerados de 1 a 9).

\section{RESULTADOS}

Acolhimento, vínculo e corresponsabilização no cuidado às pessoas com hipertensão arterial

Identifica-se a existência de diferentes formas das pessoas com HA chegarem ao serviço de saúde: 1) pelo atendimento a demanda espontânea; 2) nas visitas domiciliares, pelo agente comunitário de saúde e 3) pelo atendimento nos grupos (consultas dentro da lógica da demanda organizada). Busca-se, assim, caracterizá-las, explorando elementos referentes ao modo de funcionamento do serviço de saúde e das práticas de cuidado aos usuários com HA.

Com relação à primeira forma, apreende-se que os trabalhadores utilizam do dispositivo acolhimento como uma triagem, avaliação de riscos que hierarquiza necessidades e as diferencia conforme a queixa mais relevante. Observa-se a partir das práticas desenvolvidas pela equipe que a hipertensão arterial necessita de prioridade, pois se trata de uma necessidade clínico-biológica que urge de pronto-atendimento. Entretanto, ressalta-se que a hipertensão arterial é também determinada por fatores emocionais ligados a problemas individuais, como estresse por exemplo ${ }^{(22)}$.

Os trabalhadores de saúde enfatizam a importância de garantir atendimento, ou melhor, de priorizar atendimento às pessoas com HA. Evidente que esta abordagem biologicista é responsável pela garantia de acesso e apresenta impacto positivo no que se refere à assistência à saúde, pois concede prioridade de atendimento aos casos agudos ${ }^{(23)}$, conforme revelam as falas a seguir:

(...) Só que, assim: chegou um paciente novo na área (...) e a gente já sinta que é hipertenso ou diabético a gente já agenda ele e atende aqui na unidade mesmo. (Med2)

Se ele vier pro acolhimento, muitas vezes, na maioria das vezes não chega direto pra cá (pro consultório), eles verificam a pressão ali, aí as meninas (auxiliares de enfermagem) (...) Aí vai eu peço para vim e a gente conversa. (Enf3)

Percebe-se que há disponibilidade interna do trabalhador para acolher e atender o usuário. Mesmo que o objetivo central seja o tratamento e não o usuário, ele demonstra que não se prende tanto às regras e normas, orientando-se pela natureza do sofrimento/adoecimento e pelo direito ao atendimento, promovendo mais inclusão com responsabilização, conforme se observa na fala da auxiliar de enfermagem:

(...) Os pacientes eles não voltam pra casa sem o atendimento não, de jeito nenhum. (Aux1)

Com isso, compreende-se que a porta de entrada do CSF não limita o atendimento ao usuário com hipertensão, isto é, em relação à hipertensão, a triagem, que traz a ideia de seleção, de escolha, garante atendimento a estas pessoas devido à avaliação com classificação de risco executada no acolhimento. Contudo, vale lembrar que usuários sem $\mathrm{HA}$ que procuram o serviço de saúde por demanda espontânea não tem essa resposta, pois essa avaliação identifica apenas aqueles usuários que necessitam de algum tipo de tratamento imediato, com a priorização destes em relação à assistência ou o seu encaminhamento a outros níveis de atenção quando necessário.

Deste modo, faz-se necessário reconhecer o acolhimento como ferramenta tecnológica de intervenção que busca universalidade do acesso e mesmo mobilizado como avaliação de risco com definição de prioridades, representa importante avanço no sentido da humanização da atenção ${ }^{(14)}$.

Os usuários também enfatizam a importância dada pela equipe ao atendimento imediato, mesmo que o motivo seja a doença ou alguma queixa a ela associada.

(...) mas sempre que eu tô ali precisando, Enf1 eu estou precisando, minha pressão está alta, minha diabete não tá bem (...) Então, ela vai lá, conversa com a doutora Med1, a doutora Med1 diz: (...) a gente vai atender a Usu1, porque a Usu1 é hipertensa. (Usu1)

Identifica-se também, outra forma de acolher este usuário, numa perspectiva de acessibilidade. Caracterizando-se como uma forma pensante, atuante, desejante, carregada de subjetividades capazes de catalisar a formação de vínculos e superar barreiras físicas que separam o ambiente interno do CSF e o externo, o agente comunitário de saúde (ACS) destaca-se neste processo de garantia de acesso e de acolhimento às pessoas com HA, como podemos perceber nas seguintes falas:

(...) o agente de saúde detecta, identifica que tem um hipertenso na área dele e não tá tomando os remédios, que não ta sendo acompanhado pelo serviço (...), ele traz, eu peço o nome, agendo e o agente de saúde leva para ele o dia da consulta dele. (Enf1)

(...) o paciente ele teve um pico hipertensivo, tá em casa e o agente de saúde passa e fica sabendo, aí já facilita um pouco, porque o agente de saúde passa pra gente e a gente já pode marcar a consulta dele direto pro grupo. (Med2)

O ACS representa um sujeito de um agir singular, que integra comunidade e serviços de saúde e produz um território vivo e comum no cotidiano de sua prática, proporcionando flexibilização das tarefas com o intuito de responder positivamente às demandas da população ${ }^{(24)}$.

Percebe-se que o ACS realiza o esforço inicial de articulação e integração e, ainda, o estabelecimento de vínculos com a comunidade, desencadeando ações na perspectiva de assegurar o atendimento:

Eu acredito em um papel muito importante do agente de saúde. Por que através desse profissional que os hipertensos chegam às unidades. (Aux2) 
No que concerne ao atendimento nos grupos, adentrando neste espaço de produção de ações de saúde, observa-se conflitos e tensões, cooperação e afetos que compõem o cuidado às pessoas com HA no CSF. Percebe-se neste cenário que os trabalhadores mobilizam o acolhimento com intuito de garantir acesso desta demanda ao serviço de saúde e continuidade do acompanhamento.

$\mathrm{Na}$ busca desta garantia de acesso ao acompanhamento, a equipe desenvolve canais de comunicação com a comunidade, buscando novas formas de responder às necessidades dos usuários com $\mathrm{HA}$ e se desvinculando do modelo tradicional de atendimento. Isso implica que os trabalhadores operam o trabalho vivo em ato, pois criam o novo, questionam o instituído e sentem-se responsáveis pelos usuários ${ }^{(1)}$. Para tanto, a equipe forma e incentiva os grupos de idosos com hipertensão [a gente sempre dá uma importância para os grupos, pois é nos grupos de idosos com hipertensão que a gente percebe as necessidades deles (Enf3)], realizam escuta e diálogo [tanto a médica e a enfermeira sempre escutam os nossos problemas, às vezes nem tem a ver com a doença (Usu10)], acolhem a demanda para além do dia da consulta [a gente sempre é recebido, é escutado, mesmo se não for nosso dia do retorno (Usu1 e Usu8)] e prestam atendimento mesmo quando o usuário não é do CSF [esse paciente é hipertenso, é de outra unidade e tá sem atendimento, aí a gente faz o acolhimento e atende o paciente (Med2)].

Além disso, face à magnitude do risco no deslocamento dos usuários com $\mathrm{HA}$, muitos deles idosos, para chegar até o CSF, as equipes veem-se compelidas a buscar a alternativa de transferir seu lócus de trabalho para a comunidade:

Até pra ver a questão já pensando também no acesso deles ao atendimento, porque a localização da unidade de saúde existe uma barreira geográfica e como a gente tem muitos pacientes hipertensos que são idosos então eles sentiam muita dificuldade em atravessar a avenida (...), então isso seria melhor pra eles. (Med1)

Os trabalhadores perante as necessidades e fragilidades apresentadas pelos usuários, rompem barreiras dos consultórios e penetram no espaço vivo da comunidade, deslocam fluxos de potência para construir o novo, formar laços afetivos, num movimento de se responsabilizar pelo outro. Eles articulam e buscam aproximação e garantia de acesso dos usuários com HA, bem como demonstram disponibilidade de ajuda. Os usuários não passam pelo constrangimento da fila de espera, de ter que chegar cedo para garantir seu atendimento. Neste contexto, os grupos asseguram o dia de consulta de cada usuário.

Estes usuários, de certa forma, esperam o atendimento, porém esperam sentados, conversando com outros usuários, muitas vezes vizinhos, parentes e amigos, sem formar aglomerações próximas a consultórios ou tomados pelo cansaço da longa espera. Percebe-se que a equipe desenvolve ações de acolhimento a esses usuários, o que viabiliza o cuidado em saúde.

Logo, constata-se que estes achados são divergentes dos resultados de estudo em que, ao investigar sobre integralidade no processo de cuidar de pessoas com diabetes mellitus (DM), percebeu-se que estes usuários esperam longo tempo pelo atendimento, na maioria das vezes de pé no corredor, encostados em paredes, perto dos consultórios ou formando aglomeração em frente às portas ${ }^{(25)}$. De fato, essa realidade comunga com a proposta de Humanização ${ }^{(4,12)}$, concebida pelo Ministério da Saúde no ano de 2004, a qual objetiva, entre outras coisas, valorizar o respeito aos usuários, melhorando a infraestrutura dos serviços, respeitando a privacidade e promovendo a ambiência acolhedora e confortável.

Alguns entrevistados voltam-se para o modo como eram recebidos no CSF antes da formação dos grupos na comunidade. O CSF encontrava-se numa situação ruim de acesso ao atendimento antes da formação dos grupos nas comunidades. Sendo assim, o atendimento era organizado sem processos de acolhimento, de modo burocrático a partir de filas, por ordem de chegada, as quais privilegiavam não aqueles que necessitavam de assistência urgente, mas os que se mostravam mais resistentes ${ }^{(13,25)}$ :

Eu chegava era seis e meia, pegava uma fila e tinha que ir pra fila porque é por ordem de chegada (...) Tinha muita gente, era muito grande a fila, a gente chegava seis meia lá e já tinha muita gente. (Usu1)

Ademais, considera-se pertinente esta garantia da consulta, pois as dificuldades de acesso acabam por gerar distorções no serviço de saúde fazendo com que a porta de entrada para o atendimento se dê por meio do serviço de emergência e não pela atenção primária.

Usuários referem que nos grupos os trabalhadores atendem bem e acolhem suas necessidades. Revelam o ânimo e a preocupação dos trabalhadores de saúde para com seus problemas. Em vários momentos, por meio da observação, constataram-se atitudes dos trabalhadores buscando entender os problemas, bem como apoio e acolhimento com o intuito de diminuir os sofrimentos dos usuários.

Percebe-se que os trabalhadores realizam o acolhimento nos grupos não só na perspectiva de ampliar o acesso, mas também como elemento necessário para construção das relações no cuidado. A fala a seguir demonstra a pertinência do acolhimento na concepção de desenvolver ações comunicacionais, como postura e possibilidade de conversação entre os sujeitos ${ }^{(2)}$.

O acolhimento (...) é ele (usuário) saber que a gente sempre vai procurar tentar resolver aquele problema dele, ele saber que a gente tá aqui, e a gente sempre tá procurando ouvir e conhecer o paciente, o paciente conhecer a gente, saber os horários que a gente tá aqui. (Enf3)

Nos grupos de atendimento observa-se que os trabalhadores chegam cedo e percebem os usuários, saudando-os. Essas atitudes traduzem as formas de acolher que a equipe desenvolveu $^{(25)}$. Percebe-se, que o acolhimento também é compreendido pelos trabalhadores como postura, forma de receber e atender os usuários em qualquer momento de interação entre 
a equipe e a população ${ }^{(2)}$. Destaca-se que esta postura favorece a formação de laços afetivos, aproxima o trabalhador do usuário, aumenta a confiança, produz ações em saúde mais resolutivas e considera o contexto e o existencial da pessoa com HA.

Considerando o processo de trabalho em saúde como o modo de organização do trabalho em saúde no qual interagem tecnologias duras como os equipamentos tecnológicos, tais como máquinas, normas e rotinas; leve-duras como os saberes e modo de agir singular de cada trabalhador e leves como os aspectos inter-relacionais ${ }^{(1)}$, pode-se afirmar que $\mathrm{O}$ acolhimento às pessoas com HA no CSF investigado assume dupla dimensão, sendo, de um lado, considerado como parte de uma etapa desse processo de trabalho, sobretudo no momento da recepção dos serviços de saúde, relacionando-se ao primeiro contato com o usuário, ou seja, organizando o trabalho e de outro modo, funciona como dispositivo do processo intercessor do trabalho em saúde, uma tecnologia leve necessária em todos os lugares em que se deem encontros entre trabalhador e usuário.

Sendo assim, os trabalhadores de saúde buscavam a responsabilização clínica por meio de uma atenção acolhedora e com vínculo construído, como se percebe nas falas que se seguem:

(...) a gente fica sempre aberto a escutar, acolher independente também se for o dia do retorno ou não, então se acontecer alguma intercorrência, eles sabem a quem procurar (...) Então, a gente, fora a garantia do retorno, a gente esta sempre aberta a ouvir se eles tiverem alguma intercorrência entre uma consulta e outra. (Med1)

A partir do exposto, pode-se afirmar que acesso às pessoas com HA por meio do acolhimento nos grupos funciona como mudança, pois este dispositivo promove alteração no fluxo de entrada do usuário na unidade de saúde, desterritorializando o poder da recepção em decidir sobre o acesso ou não do usuário. O fluxo dos usuários ocorre, então, a partir de suas necessidades, mesmo que sejam apenas biológicas.

Em íntima relação com o acolhimento está o vínculo, apontado como uma das ferramentas agenciadoras das mudanças das práticas em todos os níveis e que são imprescindíveis ao fortalecimento do Sistema Único de Saúde (SUS). O vínculo precisa ser construído no cotidiano do serviço, no trabalho vivo em ato a cada momento, de forma singular, personalizada, continuada, necessitando da presença de sujeitos que protagonizam o encontro intercessor ${ }^{(1)}$.

As equipes do CSF empreendem esforços para formar laços afetivos com os usuários, num processo que envolve vínculo e corresponsabilização entre os diferentes atores do cuidado em saúde. A Política Nacional de Humanização (PNH) (4) apregoa a responsabilização como atitude de comprometimento entre trabalhadores de saúde, usuários e gestores a fim de valorizar o protagonismo desses sujeitos, a identificação das necessidades, desejos e interesses, estímulo a diferentes práticas terapêuticas e fortalecendo a organização do cuidado em rede, pois a responsabilização, como parte da relação equipe-usuário é força-motriz para o acionamento dos demais equipamentos de saúde do território, permitindo avançar na composição de ofertas de atenção à saúde de forma organizada e em sintonia com as singularidades das situações ${ }^{(12)}$.

Sendo assim, a busca por estratégias que permitam um olhar mais amplo e integral do problema relatado pelo usuário, considerando diversos aspectos que podem influir no processo saúde-doença-cuidado, faz-se possível a partir da maior aproximação que o profissional estabelece com o usuário.

As falas dos usuários são coincidentes quanto à formação do vínculo no serviço de saúde estudado. Tais falas apontam a existência de maior aproximação entre os usuários e os trabalhadores de saúde que os atendem e os acompanham. Os usuários relacionam o vínculo com o modo como os profissionais os tratam, na abertura que têm para conversar dentro e fora do espaço da consulta.

A doutora (Med1) é uma excelente profissional, dá atenção à gente, não importa que seja o dia da consulta da gente ou não. Sempre ela tá ali pra conversar (...). (Usu1)

Além disso, tais achados contrariam afirmativa de autores, segundo a qual os profissionais de saúde, sobretudo os médicos, tendem a desvalorizar o contato e o diálogo com o usuário $^{(6)}$. Como estratégias para promover esta atitude, solicitam uma bateria de exames de laboratório, consultas especializadas, que poderiam ser resolvidos no próprio Centro de Saúde. E o usuário, por sua vez, tende a valorizar a qualidade do seu atendimento pelos procedimentos complexos.

Divergindo ainda mais, constata-se que as equipes operacionalizam meios de criação de laços afetivos e de respeito para com o usuário numa perspectiva de criação de vínculos efetivos desde o início do acompanhamento. Os trabalhadores desenvolvem meios para estreitar sua relação com os usuários, como demonstram os trechos das falas:

(...) Este grupo que eu tô, que a gente acompanha. Então, assim a gente já fez várias comemorações de aniversários do grupo, né? A gente já teve passeios com eles, a gente fez festinhas, com bolo, com café da manhã, então acho que isso é uma forma de criar um vínculo com o grupo. (Enf3)

Percebe-se, então, que trabalhadores agem com a perspectiva de se aproximar do usuário e da sua necessidade, despendendo maior atenção, maior demonstração de interesse com aquele que chega ao serviço público.

Em concordância com os achados de estudo(25), as falas dos usuários são coincidentes ao afirmar sobre a satisfação com o atendimento que recebem no CSF, bem como suas relações com os trabalhadores de saúde. Eles afirmam que os profissionais atendem bem e enfatizam que os profissionais e o serviço são os melhores que já viram, pois existem outros que são muito ruins, além disso, carecem de profissionais. Os usuários entrevistados em sua maioria afirmam que gostam dos trabalhadores, porque conversam com eles e se sentem bem tratados:

Você sabe que realmente quando eu precisar dela (Med1) ela vai estar disponível para me receber, porque caso ela 
passasse por mim e não desse atenção, eu iria ficar com medo de me aproximar. (Usu1)

(...) A gente ver a loucura até dentro dos hospitais e aqui não, aqui eu acho, eu gosto muito desse espaço, deles tudinho (trabalhadores de saúde), não tenho o que dizer de nenhum. (Usu7)

Como se pode perceber, em distintos momentos, há vislumbres de acolhimento, de vínculo por parte dos usuários, o que faz com que eles se sintam bem atendidos. Muitos são pessoas simples e acostumadas com uma vida dura e qualquer atitude por parte dos trabalhadores de interesse, por menor que seja, Ihes significam grande importância ${ }^{(25)}$.

O vínculo requer a confiança do usuário em relação aos trabalhadores, no sentido dos últimos serem capazes de equacionar os problemas de saúde e, não só isso, capazes de escutar, orientar e auxiliar em outros aspectos do cotidiano da vida, inclusive no apoio ao manejo de obstáculos.

O que de fato os usuários exaltam é a postura que os trabaIhadores têm diante de suas necessidades e do compromisso que desempenham. Isto faz com que a confiança no trabaIhador se manifeste e a busca pelo profissional competente ocorra no complexo cenário das práticas de cuidado. Percebe-se que os trabalhadores sentem esta confiança, este vínculo, conforme a fala:

(...) a pressão sobe, eles vão na emergência, por exemplo, e é mudada a medicação. A maioria deles vem aqui depois, oh o doutor pediu pra eu mudar essa medicação, eu mudo? Então agente vê que realmente eles têm um vínculo. (Med1)

Assim, o usuário não vai a qualquer profissional, mas para aquele que ele já conhece e confia, aquele que ele sentiu uma disposição, uma afetuosidade e responsabilização para com ele e suas necessidades.

Percebe-se que o cuidado à pessoa com HA possui vínculo, acolhimento e responsabilização dos profissionais para com os usuários, mas sente-se distante de uma atuação corresponsável, ou seja, um cuidado compartilhado, respeitando a autonomia do sujeito em seu processo saúde-doença-cuidado. Conforme o discurso a seguir, não foi percebida corresponsabilização, apenas atenção prescritiva:

Eu pergunto, checo se ele está tomando os medicamentos direitinho, conforme está na prescrição, com relação aos horários e tudo e sempre toco nos pontos do tratamento não farmacológico, da dieta com pouco sal, se ele tá fazendo atividade física (...). (Enf1)

Com isso, surge a reflexão das práticas de cuidado, uma vez que é necessário ajudar os usuários na construção de sua autonomia, colocá-lo no centro das atenções, estimulando o seu protagonismo, criando espaços para a manifestação da sua voz, do seu pensamento, das suas ações, além de lhe proporcionar condições para viver melhor e conviver com as dificuldades relacionadas ao adoecimento e não somente centrar a atenção em prescrições multifatoriais ${ }^{(13)}$.

Quando os sujeitos com hipertensão arterial desenvolvem autonomia, é possível que conheçam cultura, saberes, práticas de cuidado, possibilitando escolhas de modo mais consciente, pela melhor forma de se cuidar ${ }^{(18)}$.

Apreende-se, também, a postura de alguns trabalhadores ao considerarem os problemas emocionais dos usuários. Mesmo com o sentimento de impotência para reverter a situação, os trabalhadores constantemente recorrem ao NASF para "resolver" problemas considerados complexos.

(...) pessoas que chegam com pico hipertensivo. Então, tem pessoas que trazem problemas, problemas familiares, eu acho que também é um momento de desabafar no momento da consulta (...) é feito uma conversa com ele e aí ele já é encaminhado para o atendimento com psicólogo do NASF. (Enf1)

Os trabalhadores referem que os usuários às vezes chegam com pico hipertensivo, agitados, com problemas emocionais e até psiquiátricos, como depressão e esquizofrenia, alguns são carentes e possuem problemas familiares, tais como: tem uns que tem os filhos usuários de drogas ou marido bebe muito (Enf2) ou certa vez eu tive que desabafar pra ela (Médica) porque meu filho tinha morrido, eu tava mal (Usu8). No entanto, demonstram certo desânimo em tentar proporcionar apoio emocional, quase não utilizam estratégias de enfrentamento conjuntas com os usuários para a resolução desses problemas. Realidade percebida durante as observações de campo e no decorrer de algumas entrevistas.

Isso reforça o o pensamento de que, com relação a usuário que chega ao CSF, ele quer ser tratado como uma pessoa que tem sua individualidade, que necessita falar de seus problemas relacionados a fatores familiares, emocionais, sociais, econômicos, entre outros ${ }^{(6)}$. Muitas vezes, como forma de desabafo, no qual o simples ouvir e chamar aquela pessoa pelo nome, demonstrando interesse pelo que é dito, já traz alívio.

Considera-se, portanto, que a transformação das práticas de saúde só poderá ocorrer mediante a valoração e centralização do/no sujeito. Desta forma, o acolhimento e o vínculo constituem importantes instrumentos na mudança desse olhar que, por tanto tempo, se centrou somente no processo da doença, esquecendo o sujeito e outros fatores, como os psicossociais, tão importantes na determinação do plano terapêutico ${ }^{(14)}$.

\section{CONSIDERAÇÕES FINAIS}

Percebe-se acolhimento e vínculo entre usuários trabalhadores de saúde que os atendem e os acompanham em seus projetos terapêuticos, sobressaindo o respeito aos usuários com HA. Além disso, a existência destes dispositivos pode ser causa do baixo número de faltosos nas consultas, evidenciado durante a permanência dos pesquisadores nos grupo. Considera-se, portanto, que a mobilização destes dispositivos é experiência exitosa no cuidado às pessoas com hipertensão 
devido ao esforço e desejo desprendidos pelos trabalhadores para garantir atendimento e acompanhamento.

No que diz respeito à responsabilização, há dificuldades relacionadas à autonomia dos usuários com $\mathrm{HA}$, isto é, considerando os conceitos presentes neste artigo, não há corresponsabilização no sentido de responsabilização mútua. Contudo, há a disponibilidade por parte dos trabalhadores de saúde para com a necessidade dos usuários, demonstrando responsabilização pelas demandas de saúde das pessoas com hipertensão arterial.

Dentre as estratégias a serem desenvolvidas, recomenda-se a reflexão dos diversos atores responsáveis pelo cuidado aos usuários com HA, inclusos enfermeiros, técnicos e auxiliares de enfermagem tão imbricados nas práticas cotidianas de saúde, para que cresça uma rede de afetos, o desenvolvimento das potências e, principalmente de ações partilhadas que estimulem a autonomia destes usuários. O cuidado necessita da garantia do acesso, da existência do acolhimento e do vínculo e de corresponsabilização para que sejam incorporadas no cotidiano dos serviços práticas produtoras de saúde.

Sendo assim, tornam-se precípuos estabelecer parcerias entre a gestão e instituições formadoras para o compartilhamento de saberes e fazeres, com retorno às comunidades dos benefícios das pesquisas; implementar processos de Educação Permanente em Saúde, principalmente no que se refere ao manejo desses dispositivos e às necessidades demandadas pelos usuários com $\mathrm{HA}$ que transcendem a dimensão biológica, como problemas sociais e/ou mentais; investir na educação em saúde e na organização de trabalho interdisciplinar, com foco na articulação equipe CSF-NASF; estimular a construção de projetos terapêuticos compartilhados e implicados com usuários, possibilitando a corresponsabilização.

A consolidação do cuidado aos usuários com HA perpassa, portanto, por aproximações entre as equipes e usuários, sensibilização e delimitação operacional e pactuação intersubjetiva os quais disparam intervenções mais efetivas e condizentes com a vida.

\section{REFERÊNCIAS}

1. Merhy EE. Saúde: a cartografia do trabalho vivo. 3. ed. São Paulo: Hucitec; 2007.

2. Santos AM, Assis MMA, Nascimento MAA, Jorge MSB. Vínculo e autonomia na prática de saúde bucal no Programa Saúde da Família. Rev Saúde Pública 2005;42(3):464-70.

3. Takemoto MLS, Silva EM. Acolhimento e transformações no processo de trabalho de enfermagem em unidades básicas de saúde de Campinas, São Paulo, Brasil. Cad Saúde Pública 2007;23(2):331-40.

4. Ministério da Saúde [homepage na interne]. Política nacional de humanização: Humaniza SUS. [acesso em 10 jun 2013]. Disponível em: http://portal.saude.gov.br/portal/arquivos/pdf/doc_base.pdf

5. Campos GWS. Reflexões sobre a clínica ampliada em Equipes de Saúde da Família. In: Campos GWS. Saúde paidéia. São Paulo: Hucitec; 2005.

6. Coelho MO, Jorge MSB. Tecnologia das relações como dispositivo do atendimento humanizado na atenção básica à saúde na perspectiva do acesso, do acolhimento e do vínculo. Ciênc Saúde Coletiva 2009;14(1):1523-31.

7. Santos AM, Assis MMA, Nascimento MAA, Jorge MSB. Vínculo e autonomia na prática de saúde bucal no programa saúde da família. Rev Saúde Pública 2008;42(3):464-70.

8. Jorge MSB, Pinto DM, Quinderé PHD, Pinto AGA, Sousa FSP, Cavalcante CM. Promoção da saúde mental e tecnologias do cuidado: vínculo, acolhimento, co-responsabilização e autonomia. Ciênc Saúde Coletiva 2011;16(7):3051-60.

9. Kearney PM, Whwlton M, Reynolds K, Muntner P, Whelton PK, He J. Global burden of hypertension: analysis of worldwide data. Lancet 2005;365(9455):217-23.
10. Ministério da Saúde. Secretaria de políticas de saúde. Departamento de ações programáticas estratégicas. Plano de reorganização da atenção à hipertensão arterial e ao diabetes mellitus: manual de hipertensão arterial e diabetes mellitus. Brasília, DF: Ministério da Saúde; 2001.

11. Castro VD, Car MR. O Cotidiano da Vida de Hipertensos: mudanças, restrições e reações. Rev Esc Enferm USP 2000;34(2):145-153.

12. Ministério da Saúde. Política Nacional de Humanização. Série B. Textos Básicos de Saúde, cadernos Humaniza Sus, v.2. p.256. Brasília: Ministério da Saúde; 2010.

13. Pires CGS, Mussi FC. Refletindo sobre os pressupostos para cuidar/cuidado na educação em saúde da pessoas hipertensa. Rev Esc Enferm USP 2009;43(1):229-36.

14. Pinheiro PM, Oliveira LC. A contribuição do acolhimento e do vínculo na humanização da prática do cirurgião-dentista no Programa Saúde da Família. Interface Comun Saúde Educ 2011;15(36):187-98.

15. Matumoto S. Encontros e desencontros entre trabalhadores e usuários na saúde em transformação: um ensaio cartográfico do acolhimento. Ribeirão Preto. Tese [Doutorado em Saúde Pública] -Escola de Enfermagem de Ribeirão Preto da USP; 2003.

16. Fernandes MTO, Silva LB, Soares SM. Utilização de tecnologias no trabalho com grupos de diabéticos e hipertensos na Saúde da Família. Ciênc Saúde Coletiva 2011;16(Suppl.1):1331-40.

17. Secretaria Municipal de Saúde [homepage na internet]. Relatório de gestão do ano de 2007 da Secretaria Municipal de Saúde de Fortaleza: saúde, qualidade de vida e a ética do cuidado [acesso em 12 out 2010]. Disponível em: http://www.sms.fortaleza.ce.gov.br.

18. Fontanella BJB, Ricas J, Turato ER. Amostragem por 
saturação em pesquisas qualitativas em saúde: contribuições teóricas. Cad Saúde Pública 2008;24(1):17-27.

19. Conselho Nacional de Saúde. Comissão Nacional de Ética em Pesquisa - CONESP. Normas para pesquisas envolvendo seres humanos. Resolução CNS 196/96. Serie Cadernos Técnicos. Brasília: Ministério da Saúde; 1996. p.138.

20. Minayo MCS. O desafio do conhecimento: pesquisa qualitativa em saúde. 11. ed. São Paulo: Hucitec; 2008.

21. Bardin L. Análise de conteúdo. Lisboa: Lidel; 2009.

22. Nobrega ACL, Castro RRT, Souza AC. Estresse mental e hipertensão arterial sistêmica. Rev Bras Hipertens
2007; 14(2):94-7.

23. Tesser CD, Poli Neto P, Campos GWS. Acolhimento e (des)medicalização social: um desafio para as equipes de saúde da família. Ciênc Sáude Coletiva 2010;15(supl.3):3615-24.

24. Rodrigues AAAO, Santos AM, Assis MMA. Agente comunitário de saúde: sujeito da prática em saúde bucal em Alagoinhas, Bahia. Ciênc Saúde Coletiva 2010;15(3):907-15.

25. Bastos LS, Assis MMA, Nascimento MAA, Oliveira LCF. Construção da integralidade no cuidar de pessoas com diabetes mellitus em um centro de saúde em Feira de Santana (BA). Ciênc Saúde Coletiva 2011;16(suppl.1):1417-1426. 